\title{
Nanoindentation Size Effect of Tungsten Single Crystal
}

\author{
Zhang Wen ${ }^{1,2}$, Gao Xuanqiao ${ }^{2}$, Zhang Pingxiang ${ }^{1,2}$, Hu Zhongwu ${ }^{2}$, Li Laiping ${ }^{2}$, \\ Cheng Jun ${ }^{2}$
}

${ }^{1}$ Northwestern Polytechnical University, Xi'an 710072, China; ${ }^{2}$ Northwest Institute for Nonferrous Metal Research, Xi'an 710016, China

\begin{abstract}
The load-displacement curves, elastic modulus, indent morphology, nanohardness and elastic recovery of high purity tungsten single crystal were investigated by nanoindentation and scanning probe microscopy. Results show that W (111) crystal plane undergoes elastic deformation and plastic deformation during the loading-unloading process, and the load-displacement curve does not show discontinuity, which demonstrates that cracks and brittle fracture are not formed in the indents. Moreover, the pile-up behavior around indents reveals that tungsten single crystal has a low work hardening tend. The nanohardness and elastic modulus of tungsten single crystal were measured by continuous stiffness measurement (CSM), and a size effect on the nanohardness and elastic modulus of tungsten single crystal was observed, which decrease with the increase of indentation depth. The Nix-Gao model was employed to analyze the nanoindentation mechanical characteristics of tungsten single crystals, and the characteristic length $\left(h^{*}\right)$, the intrinsic hardness in the limit of infinite depth $\left(H_{0}\right)$ and size effect index $(m)$ were calculated to be $1490 \mathrm{~nm}, 6.79 \mathrm{GPa}$ and 0.18 , respectively, which indicates that tungsten single crystal has a significant size effect when the indentation depth is below $1490 \mathrm{~nm}$, and the size effect becomes more insignificant when indentation depth is above $1490 \mathrm{~nm}$. When the impression is deeper than 2450 $\mathrm{nm}$, the nanoindentation size effect on the hardness will disappear.
\end{abstract}

Key words: tungsten single crystal; nanoindentation; elastic modulus; indentation size effect

High temperature structural materials are required to have high elasticity, high plasticity, and a low creep rate at elevated temperatures. Tungsten, molybdenum and their alloys are widely used in modern science and technology due to the excellent stability of microstructure such as nuclear technology, high temperature reactor, ITER metal shell, and cathode of X-ray tube and so on. These components demand stable microstructure and mechanical properties at high temperature $\left(1500 \sim 2500{ }^{\circ} \mathrm{C}\right)^{[1]}$. Tungsten can be widely used as high temperature structural materials due to the high strength and creep resistance rate. However, polycrystalline tungsten will fail during long period application at high temperature. Tungsten single crystal has significant advantages compared with polycrystalline tungsten, such as no grain boundaries, no recrystallization at high temperature, the stability of microstructure and performances below the melting point. The Mo single crystal has been replaced by high purity tungsten single crystals partly in the aerospace field because of its excellent performances $^{[2]}$. Therefore, it's necessary to carry out fundamental research systematically on the properties of tungsten single crystals to promote its development and application $^{[3]}$.

At present, the material science system based on dislocation theory has been established, while the mechanism of the initial homogeneous dislocation at the nano-scale needs to be studied further due to the lack of effective methods to observe the microstructural evolution at atomic scale ${ }^{[4,5]}$. The single crystals can be used to reveal the micro- and nano-scale initial plastic deformation behavior of non-defective crystal materials because of the simplest crystal structure. Some researchers have carried out studies on the nanoindentation behavior of some fcc metal single crystals such as $\mathrm{Ag}^{[6]}, \mathrm{Cu}^{[7,8]}, \mathrm{Au}^{[9]}$ and $\mathrm{Ir}^{[10]}$, but few of tungsten single crystals with bcc structure. It's quite difficult to process the tungsten single crystals 
because the plastic deformation behavior of tungsten single crystals is similar to the intermetallic compounds and shows intrinsic brittleness ${ }^{[11]}$. In this paper, the loaddisplacement curve, elastic modulus, indent morphology, nanohardness and elastic recovery of high purity tungsten single crystals $(<111\rangle$ orientation) were investigated by nanoindentation and scanning probe microscopy. Moreover, the Nix-Gao model was employed to analyze the nanoindentation mechanical characteristics.

\section{Experiment}

The high purity tungsten single crystals rods of <111> orientation fabricated by electron beam floating zone melting were provided by Northwest Institute for Nonferrous Metal Research, and a sample with size of 10 $\mathrm{mm} \times 10 \mathrm{~mm} \times 1 \mathrm{~mm}$ was cut off along the axial direction. The measured orientation deviation angle $\theta$ is $0^{\circ[12]}$, and the rocking curve is shown in Fig.1. In order to ensure the accuracy and consistency of the experimental results of nanoindentation, the surface of the sample was electrochemically polished, and the roughness measured by atomic force microscopy is about $2 \mathrm{~nm}$ as shown in Fig.2. The nanoindentation tests were performed by employing TriboIndenter system (HysitronTI-950 TriboIndenter) equipped with a Berkovich diamond pyramid indenter which was also used as a scanning probe microscopy (SPM) tip and the indented surfaces were photoed immediately after nanoindentation. For Berkovich diamond pyramid indenter, centerline-to- face angle, centerline-to-edge angle, radius at the apex and displacement resolution are $65.3^{\circ}$, $77.05^{\circ}, 50 \mathrm{~nm}$ and $0.01 \mathrm{~nm}$, respectively. The loading depth were set to 50,100, 150 and $200 \mathrm{~nm}$, and the load was held for $10 \mathrm{~s}$. In order to ensure that the test points do not affect each other, the distance between each two indents was set to $100 \mu \mathrm{m}$. The average data of 5 repeated measurements was calculated for each loading depth. Nanoindentations tests were carried out at the constant temperature of $20^{\circ} \mathrm{C}$.

\section{Results and Discussion}

\subsection{Load-displacement curves}

The whole indentation process includes loading and unloading. The indenter is pressed into the surface of the materials and the indentation depth will increase with the increasing of loading during loading process, and load will be removed when the indentation depth reaches the maximum value. Only elastic displacement can be restored in the unloading process, so the hardness and elastic properties can be analyzed from the unloading curve. For ideal elastic materials, the loading curve and unloading curve is overlapped due to the plastic deformation is inexistent. To the contrary, unloading curve of ideal plastic materials is perpendicular to the displacement axis since

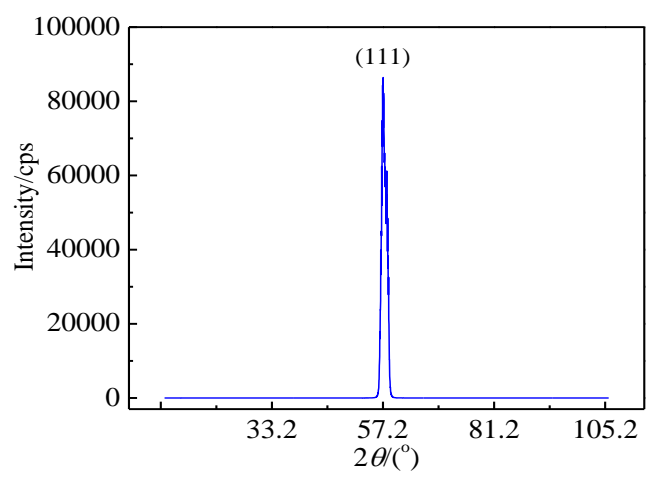

Fig.1 XRD pattern of tungsten single crystal

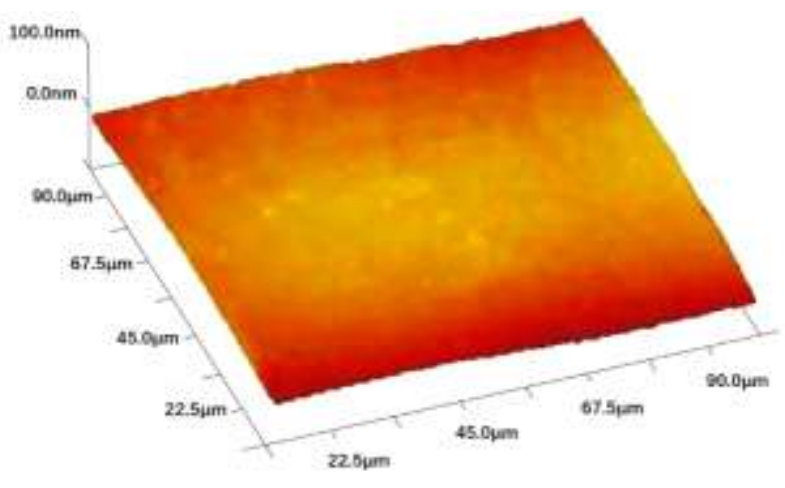

Fig.2 Surface of the tungsten single crystal measured by atomic force microscopy

there is no elastic deformation. In fact, ideal elastic or plastic deformation do not exist during nanoindentation, and materials undergo elastic deformation and plastic deformation during loading-unloading process. It's a critical point for the transition of elasticity and plasticity when the load is constant and the displacement changes.

Fig.3 displays the representative nanoindentation load-displacement curves for the indentation depth range from 50 to $200 \mathrm{~nm}$. As shown in Fig. 3, the loaddisplacement curves show obvious fluctuation during the loading process when the indentation depth is shallow $(<50$ $\mathrm{nm})$, which is attributed to the oxidization and work hardening on the sample surface. After unloading, the displacement was not fully recovered, and residual impression remained, which indicates irreversible plastic deformation of $\mathrm{W}$ single crystal during the loading process. It is well known that the pop-in and pop-out during loading process are usually observed in the nanoindentation of many kinds of materials, and the yield discontinuity is attributed to the initiation of dislocation or crack ${ }^{[13]}$. In our experiment, there is no discontinuity in the load- 

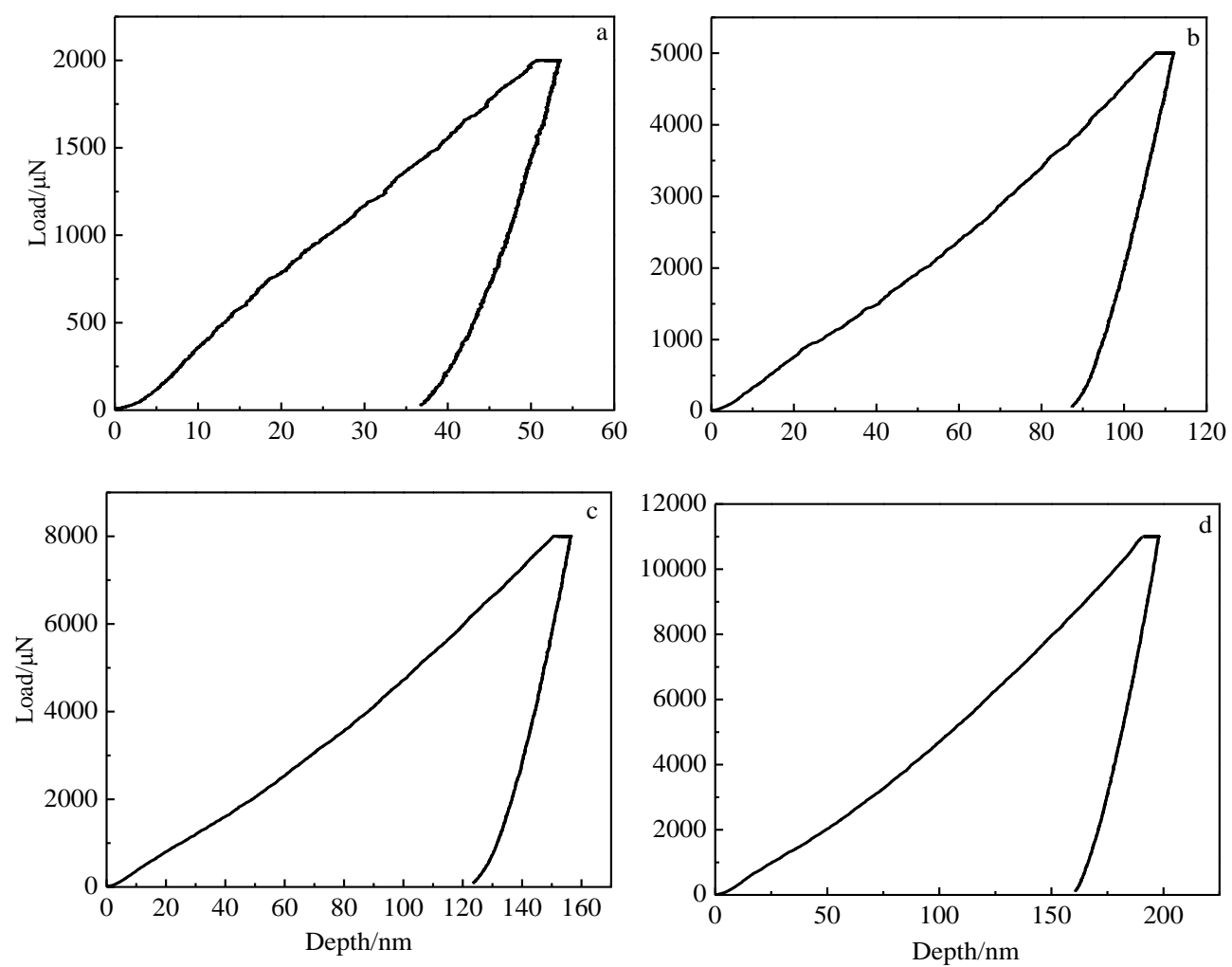

Fig.3 Load-depth curves of tungsten single crystals in nanoindentation test under different indentation depth: (a) $50 \mathrm{~nm}$, (b) $100 \mathrm{~nm}$, (c) $150 \mathrm{~nm}$, and (d) $200 \mathrm{~nm}$

displacement curves within a depth of $200 \mathrm{~nm}$ indicating that the cracks and dislocations are not formed in $\mathrm{W}$ single crystal during loading and unloading.

Table 1 shows the elastic recovery rate of $\mathrm{W}(111)$ plane, where $h_{\mathrm{d}}$ is the setting impression depth, $h$ is the maximum impression depth, $P$ is the maximum load, $h_{\mathrm{f}}$ is the residual impression depth, and $R$ is the elastic recovery rate. The maximum elastic recovery rate is $36.1 \%$, when the indentation depth is $50 \mathrm{~nm}$. With the increase of the indentation depth, the elastic recovery rate decreases gradually. When the indentation depth is about $200 \mathrm{~nm}$, the elastic recovery rate is $19.3 \%$, indicating that plastic deformation increases with the increase of the indentation depth in W single crystal during loading process.

\subsection{Morphology of residual impression}

Table 1 Elastic recovery rates under different contact depth of W(111) crystal plane

\begin{tabular}{ccccc}
\hline$h_{\mathbf{d}} / \mathrm{nm}$ & $h / \mathrm{nm}$ & $P / \mu \mathrm{N}$ & $h_{\mathrm{f}} / \mathrm{nm}$ & $R / \%$ \\
\hline 50 & 54.41 & 2000 & 34.76 & 36.1 \\
100 & 112.08 & 5000 & 88.15 & 21.3 \\
150 & 159.17 & 8000 & 127.48 & 19.9 \\
200 & 197.95 & 11000 & 159.65 & 19.3 \\
\hline
\end{tabular}

Fig.4 shows the SPM images of residual impression loaded to $100 \mathrm{~nm}$. Generally, plastic deformation in nanoindentation occurs mainly by slip on certain slip systems, causing either pile-up or sink-in in the vicinity of the indent, which is related to materials with high work hardening tendency, such as annealed $\mathrm{Cu}$ single crystal ${ }^{[14]}$, sink-in effect is significant because work hardening suppresses the atom flow around the indenter, while pile-up is observed in the materials with low work hardening tendency ${ }^{[15,16]}$, such as Ir single crystal ${ }^{[17]}$. In this paper, the pile-up was observed around each residual impression in tungsten single crystal and became more significant with increasing of indentation depth. The amount of pile-up can be characterized by the height of the pile-up compared to the undeformed surface and the pile-up height decreases for tensile stress and increases for compressive stress ${ }^{[18]}$. The occurrence of stress-free state pile-up reveals that pile-up is not only influenced by the residual stress but also influenced the low hardness and small strain hardening exponent of tungsten single crystal. For tensile residual stress, the materials were pulled away from the surface of indenter, which decreased the amount of pile-up, while compressive stress pushed the materials out to the surface of indenter resulting in more pile-up. 

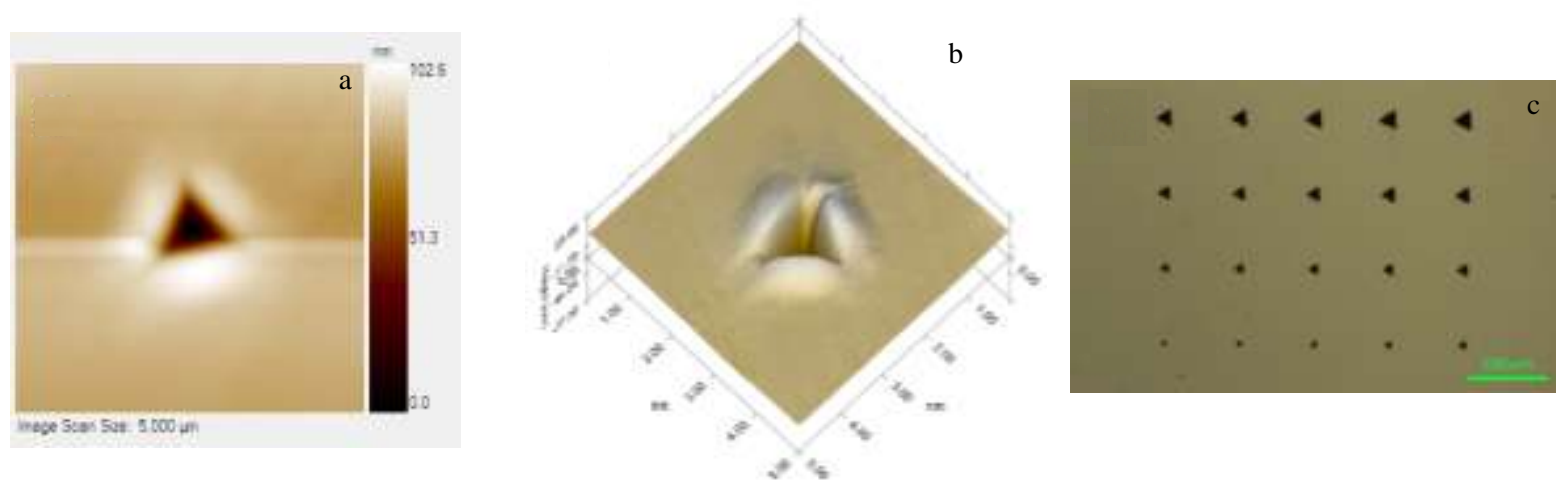

Fig.4 Nano-Indenter images of the indenting of W (111) single crystals under $100 \mathrm{~nm}$ indentation depth: (a) indentation surface topography, (b) three-dimensional topography, and (c) macro topography

\subsection{Relationship between nanohardness and depth}

Fig.5 shows the schematic diagram of surface deformation during loading and unloading. Based on the data obtained from the load-displacement curve, the nanohardness and elastic modulus of specimen can be calculated using the Oliver-Pharr method ${ }^{[19]}$.

Although the hardness of materials used for indenter is very high, in the process of indenter contact with the materials, indenter and materials will have a degree of deformation, so the definition of reduced modulus $E_{\mathrm{r}}$ is satisfied in the form:

$$
\frac{1}{E_{\mathrm{r}}}=\frac{1-v_{\mathrm{s}}^{2}}{E_{\mathrm{s}}}+\frac{1-v_{\mathrm{i}}^{2}}{E_{\mathrm{i}}}
$$

Where $E_{\mathrm{s}}$ is the elastic modulus of materials, $E_{\mathrm{i}}$ is elastic modulus of indenter, $v_{\mathrm{s}}$ and $v_{\mathrm{i}}$ is Poisson's ratio of materials and indenter, respectively. For Berkovich indenter (diamond pyramid) and tungsten single crystals, $E_{\mathrm{i}}=1141 \mathrm{GPa}, v_{\mathrm{i}}=0.07$ and $v_{\mathrm{s}}=0.2$. Furthermore, $E_{\mathrm{r}}$ is related to the unloading curve and as follows:

$$
E_{\mathrm{r}}=\frac{\sqrt{\pi}}{2 \beta} \frac{S}{A}
$$

Where $\beta$ is the shape factor of the indenter. For Berkovich indenter, $\beta=1.058$. $S$, namely contact stiffness, is the tangent of the maximum value on the unloading curve and can be represented by the following form:

$$
S=\left[\frac{\mathrm{d} P}{\mathrm{~d} h}\right]_{h_{\max }}
$$

$A$ is the area of the projection of the indent on the surface of the specimen, the contact area $A$ is as follows:

$$
A=24.56 h_{\mathrm{c}}^{2}
$$

Where $h_{\mathrm{c}}$ is the contact depth, and $P$ is the load on the indenter. According to mechanics theory, the nanohardness $H$

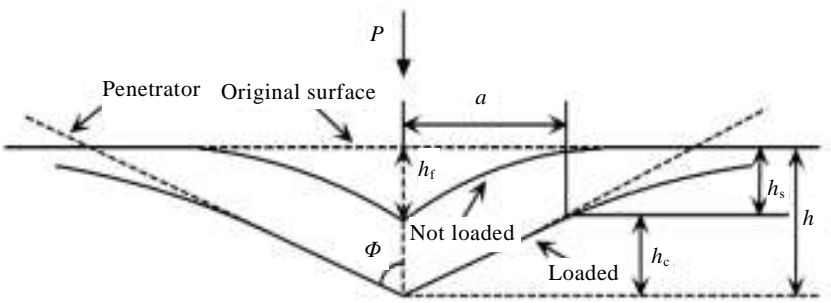

Fig.5 Schematic diagram of surface deformation during loading and unloading

can be expressed as:

$$
H=P / A
$$

Since the Oliver-Pharr method is based on elastic theory, therefore, the nanohardness can be calculated only when effective indentation depth is less than the maximum indentation depth. The contact area obtained by Oliver-Pharr method is smaller than the actual contact area, so the calculated nanohardness value is higher than true hardness ${ }^{[20]}$.

Fig.6 displays the effect of maximum displacement on the hardness and elastic modulus of W(111) single crystal. For the maximum contact depth of $30 \mathrm{~nm}$, the hardness and elastic modulus are 7.82 and $270.2 \mathrm{GPa}$, respectively. With increasing of maximum contact depth, the hardness and elastic modulus decrease to 6.36 and $259.8 \mathrm{GPa}$ for the maximum contact depth of $190 \mathrm{~nm}$, respectively. For shadow indentation, hardness decreases more significantly than elastic modulus due to surface stress distribution and work hardening. When the maximum contact depth exceeds $50 \mathrm{~nm}$, the decreasing tendency is similar, which indicates size effect. There are several reasons for size effect. From the aspect of mechanics, low loading pushed the indenter into the surface 

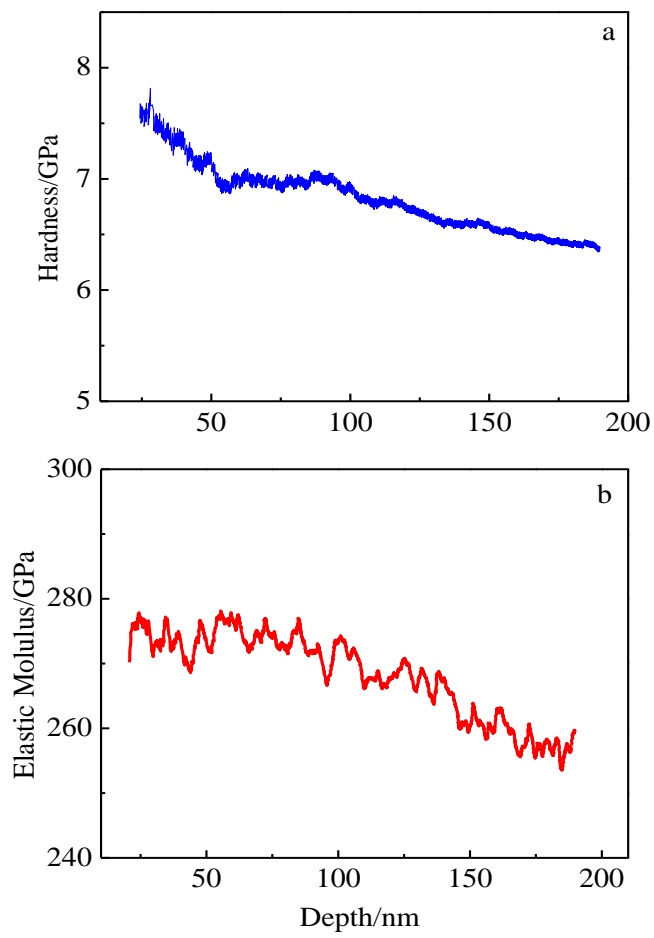

Fig.6 Dependence of nanohardness (a) and elastic modulus (b) on indentation depth for $\mathrm{W}(111)$ single crystals

of the sample, and the hardness and elastic modulus are strongly dependent on surface stress distribution and work hardening, such as plastic deformation and residual stress introduced by sample preparation. The work effect of indenter was consumed by plastic deformation when the indenter was pushed to the interior of sample. Therefore, the nanohardness decreases gradually and shows indentation size effect $^{[21]}$.

\subsection{Model of the relationship between nanohardness and depth}

At present, the commonly accepted Nix-Gao model ${ }^{[21,22]}$ is based on the strain gradient theory ${ }^{[23]}$. This model suggests that the nanoindentation size effect is attributed to the change of geometrically necessary dislocations density induced by the strain gradient in materials, which can explain the influence of geometrically necessary dislocations and statistically stored dislocations on plastic deformation and strain gradient. The results obtained during the nanoindentation agree well with this model using the concept of geometrically necessary dislocations. In the Nix-Gao model, the density of geometrically necessary dislocations is expressed as ${ }^{[21]}$ :

$$
\rho_{\mathrm{G}}=\frac{3}{2 b h} \tan ^{2} \theta
$$

where $\theta$ is the angle between the surface of the conical indenter and the plane of the surface (for Berkovich indenter simplified as a conical indenter, $\theta$ is $\left.70.3^{\circ}\right), h$ is the depth of indentation, and $b$ is Burger's vector. Considering together with Taylor's dislocation strengthening model and Von Mises flow rule, the relation between the indentation hardness and the indentation depth can be simply described as ${ }^{[24,25]}$ :

$$
H^{2}=H_{0}^{2}+H_{0}^{2} \frac{h^{*}}{h}
$$

where $H$ is indentation hardness, $h$ is indentation depth, $H_{0}$ is the intrinsic hardness in the limit of infinite depth, and $h^{*}$ is the characteristic length that characterizes the depth dependence of the hardness, which is expressed as:

$$
h^{*}=\frac{81}{2} b \alpha^{2} \tan ^{2} \theta_{0}\left(\frac{G}{H_{0}}\right)^{2}
$$

where $\alpha$ is Taylor factor, and $G$ is shear modulus, which are taken as 0.38 and $123 \mathrm{GPa}$, respectively. Using the Nix-Gao model, $H_{0}$ of $\mathrm{W}(111)$ single crystal was calculated to be $6.79 \mathrm{GPa}$, which can be considered as the reference value of nanohardness. Moreover, $h^{*}$ was calculated to be $1490 \mathrm{~nm}$, W single crystal has a significant size effect when the indentation depth is below about $1490 \mathrm{~nm}$, and the size effect becomes more insignificant than indentation depth. According to further calculation with $H_{0}$, the indentation size effect will disappear when the loading depth of W(111) single crystal exceeds $2450 \mathrm{~nm}$, and the hardness value is a constant, which may be a guide for the hardness tests of $\mathrm{W}$ single crystal. The maximum indentation depth can only reach to about $200 \mathrm{~nm}$ due to the low loading indenter (the maximum load is $10 \mathrm{mN}$ ). Therefore, the following experiment with large loading indenter will be conducted to verify the calculated $H_{0}$ and $h^{*}$ in this paper.

Manika et al $^{[26,27]}$ confirmed the power-law relation between nanohardness and depth:

$$
H=C h^{-m}
$$

Where $C$ is a constant, and $m$ is the power-law exponent which is related to the degree of indentation size effect. Taking the natural logarithm on both side of Eq.(9), $\lg H$ and $\lg (1 / h)$ have a linear relationship. The linear relationship between $\lg H$ and $\lg (1 / h)$ for $\mathrm{W}$ single crystal is shown in Fig.7, and $m$ is calculated to be 0.18 by curve fitting. For single crystal of metals and semiconductors, $m$ varies from 0.12 to 0.32 depending on the material ${ }^{[26]}$. Generally, when the plasticity (or hardness) of the materials is higher, the value of $m$ is larger. For instance, semi-metallic $\mathrm{Sb}$ has the most significant indentation size effect with a $m$ value of 0.32 , and $m$ value of semiconductor $\mathrm{Si}$ is 0.2 . Sn and $\mathrm{In}$ have good plasticity, and their $m$ values are similar to the metals such as $\mathrm{Au}, \mathrm{Ag}$ and $\mathrm{Cu}$. Moreover, Ir has the same face-centered cubic crystal structure as $\mathrm{Au}, \mathrm{Ag}$ and $\mathrm{Cu}$, but its $m$ value is much larger, which indicates that there is no necessary correlation between crystal structure and $m$ value ${ }^{[17]}$. Polycrystalline tungsten has poor processing properties and 


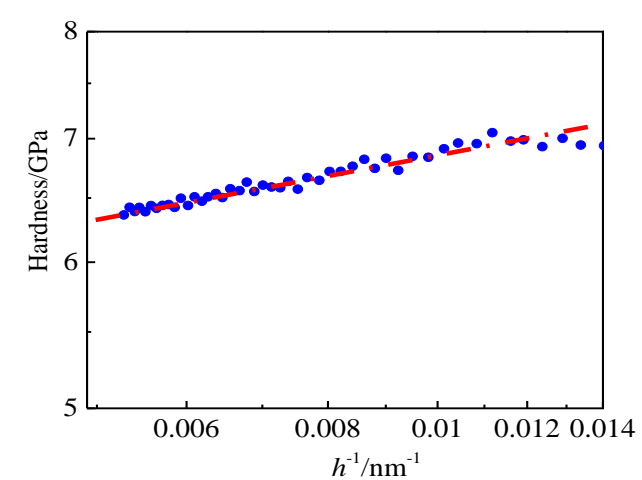

Fig.7 Dependence of nanohardness $(H)$ on indentation depth $(1 / h)$ for W(111) single crystal

high ductile brittle transition temperature ${ }^{[28]}$. However, W single crystal has lower deformation resistance and better plasticity due to dislocations movement without obstacles of grain boundary ${ }^{[29]}$. The calculated $m$ of W single crystal is relatively low denoting that the plasticity of $\mathrm{W}$ single crystal is better than that of polycrystalline tungsten on the other hand.

\section{Conclusions}

1) $\mathrm{W}$ single crystals undergo elastic and plastic deformation during loading and unloading, and there is no discontinuity in the load-displacement curve within a depth of $200 \mathrm{~nm}$, which indicates that the cracks are not formed in W single crystal during loading.

2) Morphology of residual impression shows pile-up, which reveals that $\mathrm{W}$ single crystal has low work hardening trend.

3) The elastic modulus of W single crystal is measured to be $278 \mathrm{GPa}$ by continuous stiffness measurement, and the nanohardness and elastic modulus decrease with the increase of indentation depth, showing nanoindentation size effect. According to Nix-Gao model, intrinsic hardness in the limit of infinite depth $H_{0}$, characteristic length $h^{*}$, and size effect index $m$ are calculated to be $6.79 \mathrm{GPa}, 1490 \mathrm{~nm}$ and 0.18 , respectively. When the impression is deeper than $2450 \mathrm{~nm}$, the nanoindentation size effect on the hardness will disappear.

\section{References}

1 Glebovsky V. Crystal Growth: Substructure and Recrystallization[M]. Rijeka: Intech, 2012: 59

$2 \mathrm{Hu}$ Z W\, Li Z K, Zhang Q et al. Nonferrous Metals[J], 2008, 60(2): 1 (in Chinese)

$3 \mathrm{Hu}$ Z W, Li Z K, Yin T et al. Chinese Journal of Rare Metals [J], 2000, 34(1): 48 (in Chinese)
4 Dursk K, Franke O, Böhner A et al. Acta Materialia[J], 2007, 55(20): 6825

5 Jang J, Yoo B, Kim Y et al. Scripta Materialia[J], 2011, 64(8): 753

6 Ma Q, Clarke D R. Journal of Materials Research[J], 1995, 10: 853

7 Liu Y, Varghese S, Ma J et al. International Journal of Plasticity[J], 2008, 24: 1990

8 Zhu A, He D Y, He R J et al. Materials Science \& Engineering $A[\mathrm{~J}], 2016,674: 76$

9 Knap J, Ortiz M. Physical Review Letters[J], 2003, 90(22): 6273

10 Yao T, Liu Y, Li Zeli et al. Precious Metals[J], 2016, 37(1): 27 (in Chinese)

11 Brunner D, Glebovsky V. Materials Letters[J], 2000, 42: 290

12 Guo Z Q, Fu T, Fu H Z. Materials Characterization[J], 2000, 44(4-5): 431

13 Soifer Y M, Averdyan, Rapoport L. Materials Letters[J], 2002, 56(3): 127

14 Poole W J, Ashby M F, Fleck N A. Scripta Materialia[J], 1996, 34(4): 559

15 Mcelhaney K W, Vlassak J J, Nix W D. Journal of Materials Research[J], 1998, 13(5): 1300

16 Giannakopoulos A E, Suresh S. Scripta Materialia[J], 1999, 40: 1191

17 Cawkwell M J, Nguyen-Manh D, Woodward C et al. Science[J], 2005, 309(5737): 1059

18 Zhu L N, Xu B S, Wang H D et al. Materials Chemistry and Physics [J], 2012, 136: 561

19 Oliver W, Pharr C et al. Journal of Materials Research[J], 1992, 7(6): 1564

20 Dong M L, Jin G, Wang H D.et al. Materials Review[J], 2014, 28(3): 107 (in Chinese)

21 Nix W D, Gao H J. J Mech Phys Solids[J], 1998, 46(3): 411

22 Dursk K, Franke O, Böhner A et al. Acta Materialia[J], 2007, 55(20): 6825

23 Fleck N A. Acta Metall Mater[J], 1994, 42(2): 475

24 Jang J, Yoo B, Kim Y et al. Scripta Materialia[J], 2011, 64(8): 753

25 Mao W G, Shen Y G, Lu C. Scripta Materialia[J], 2011, 65(2): 127

26 Manika I, Maniks J. Acta Materialia[J], 2006, 54: 2049

27 Milman Y V, Golubenko A A, Dub S N. Acta Materialia[J], 2011, 59(20): 7480

28 Wang F Z, Tang L X, Feng P F et al. Tungsten Materials and Their Processing[M]. Beijing: Metallurgical Industry Press, 2008: 10 (in Chinese)

29 Lyakishev N P, Burkhanov G S. Metallic Single Crystals[M]. Moscow: Eliz, 2002: 165 


\title{
铇单晶纳米压痕尺寸效应研究
}

张 文 $^{1,2}$, 高选乔 ${ }^{2}$, 张平祥 ${ }^{1,2}$, 胡忠武 ${ }^{2}$, 李来平 ${ }^{2}$, 程 军 $^{2}$

(1. 西北工业大学, 陕西 西安 710072)

(2. 西北有色金属研究院，陕西 西安 710016)

\begin{abstract}
摘 要: 利用纳米压痕仪和扫描探针显微镜对高纯铇单晶的载荷-位移曲线、弹性模量、压痕形貌、纳米硬度-加载深度以及弹性回复 率的变化情况进行了研究。结果表明, W(111)晶面在加载和卸载过程中分别经历了弹性变形和塑性变形阶段, 荷载-位移曲线未出现不 连续现象, 表明在加载过程中压痕内部未产生裂纹或脆性断裂; 铇单晶的残余压痕表现出堆积形貌, 表明铇单晶有较低的加工应变硬 化趋势; 采用连续刚度法测量了铇单晶的纳米压痕硬度以及弹性模量, 结果表明, 铇单晶纳米压痕硬度和弹性模量存在尺寸效应, 即 随着加载深度的增加, 单晶的纳米压痕硬度和弹性模量减小; 采用 Nix-Gao 模型对铇单晶的纳米压痕力学特征进行了分析, 计算了铇 单晶的微观特征长度 $\left(h^{*}\right)$ 为 $1490 \mathrm{~nm}$, 无压痕尺寸效应时的纳米硬度值 $\left(H_{0}\right)$ 为 $6.79 \mathrm{GPa}$, 尺寸效应因子 $(m)$ 为 0.18 , 即压入深度 小于 $1490 \mathrm{~nm}$ 时, 铇单晶具有明显的尺寸效应, 当压入深度超过 $1490 \mathrm{~nm}$ 时, 尺寸效应将减弱。当压入深度超过 $2450 \mathrm{~nm}$ 时, 铇单晶 的纳米尺寸效应将消失。
\end{abstract}

关键词: 铇单晶; 纳米压痕; 弹性模量; 压痕尺寸效应

作者简介: 张 文, 男, 1981 年生, 博士生, 高级工程师, 西北工业大学, 陕西 西安 710072, 电话: 029-86231082, E-mail: gwenzh@163.com 